\section{EL PASADO MEXICANO EN LA LITERATURA "COLONIALISTA»}

\author{
TEODOSIO FERNÁNDEZ
}

A partir de 1917, coincidiendo con el fin de la guerra revolucionaria, se desarrolló en México la literatura «colonialista», que prolongaría su vigencia aproximadamente hasta 1926, aunque los escritores que la representaron habían de continuar enriqueciéndola con aportaciones diversas en años posteriores. Fue la faceta creativa de un grupo de estudiosos de historia, arte y literatura entre los que se contaron Francisco Monterde, Julio Jiménez Rueda, Ermilo Abreu Gómez, Artemio de Valle-Arizpe, Genaro Estrada, Alfonso Cravioto y -aunque en su caso la producción literaria quedara totalmente oscurecida por su trabajo como crítico y por su dedicación a la historia del arte mexicano- Manuel Toussaint. No surgían de la nada: avanzaban por el camino que antes del estallido de la Revolución habían abierto grandes interesados en la época colonial, como Luis González Obregón -con obras como México viejo (1891-1895) y La vida en México en 1810 (1911)- y Manuel Romero de Terreros y Vinent, Marqués de San Francisco, que seguían en activo y durante varias décadas habían de contribuir al enriquecimiento de las publicaciones sobre los mismos temas.

Los años en los que se desarrolló justifican en buena medida el interés del colonialismo y a la vez explican su fin. Sus manifestaciones han podido interpretarse como «un movimiento de huida hacia el pasado, determinado por la angustia de la Revolución»" ${ }^{1}$, pero lo cierto es que no hacía sino continuar y culminar una visión entre pintoresca y nostálgica del virreinato que había contado con diversas manifestaciones previas. Entre las obras mencionadas de González Obregón y Las calles de México que él publicó entre 1922 y 1927 no se per- cibe ningún cambio significativo, y tampoco entre los «apuntes biográficos» que Romero de Terreros dio a conocer antes de la Revolución -sobre Juan Gómez de Parada, obispo de Yucatán, Guatemala y Guadalajara, en 1908; sobre los condes de Regla en 1909- y libros posteriores suyos como Ex antiquis. Bocetos de la vida social en Nueva España (1919) o Las artes industriales en la Nueva España (1923). Con sus estudios, uno y otro hicieron fáciles los versos que Alfonso Cravioto reunió en El alma de las cosas viejas (1921), según expresaba el agradecimiento del autor. Ese poemario prueba que el colonialismo no sólo se concretó en sus diferentes manifestaciones en prosa, y además permite constatar que contaba también con el impulso hispanófilo que Rubén Darío había dado al modernismo a partir de 1898. Estos versos de su «Canto final» son suficientemente explícitos:

Y la aurora devana sus capullos de raso; impacientes relinchan Clavileño y Pegaso; y revuelos de amores cruzan el oceano: se clavan las pupilas en el solar hispano, y porque España trajo, prendida a su bandera, en plenitud su vida, y su alma toda entera, porque ella nos dio todo lo que tuviera entonces, fundiendo en sus crisoles su acero y nuestros bronces, y porque en lo más alto de nuestros ideales se sienten todavía sus ansias maternales: en gratitud de siglos, en ímpetu devoto, en honor a la herencia del pasado remoto, ponemos, con ternura que los ojos empaña, besos definitivos en la frente de España!

Desde esa perspectiva el colonialismo no fue tanto una literatura que trataba de evadirse de la realidad posterior a la guerra revolu-

\footnotetext{
Teodosio Fernández

Catedrático de literatura hispanoamericana de la Universidad Autónoma de Madrid. Su actividad docente e investigadora se ha centrado fundamentalmente en la literatura hispanoamericana de los siglos XIX y XX y la significación de los procesos políticos $\mathrm{y}$ culturales en ésta. Entre sus publicaciones se cuentan: El teatro chileno contemporáneo (1941-1973) (1982), La poesía hispanoamericana en el siglo XX (1987), La poesía hispanoamericana hasta el final del modernismo (1989), Los géneros ensayísticos hispanoamericanos (1990) y Literatura hispanoamericana: sociedad y cultura (1998). Ha editado Amalia de José Mármol (1984), Huasipungo de Jorge Icaza (1994) y Garduña de Manuel Zeno Gandía (1996), así como el volumen Teoría y crítica literaria de la emancipación hispanoamericana (1997).
}

1 Véase «El colonialismo» en José Luis Martínez, Literatura mexicana siglo XX. 1910-1949, primera parte, México, Antigua Librería Robredo, 1949, pp. 18-20 (18)

2 Alfonso Cravioto, El alma nueva de las cosas viejas. Poesías, México, Ediciones México Moderno, MCMXXI, p. 196. Conviene recordar que Cravioto había colaborado en la modernista Revista Moderna de México (1903-1911), y además en 1906 había sido mecenas y codirector de Savia Moderna, revista que se relaciona con la irrupción de los futuros miembros del Ateneo de la Juventud en la escena literaria mexicana

El pasado mexicano en la literatura
«colonialista" TEODOSIO FERNÁNDEZ 


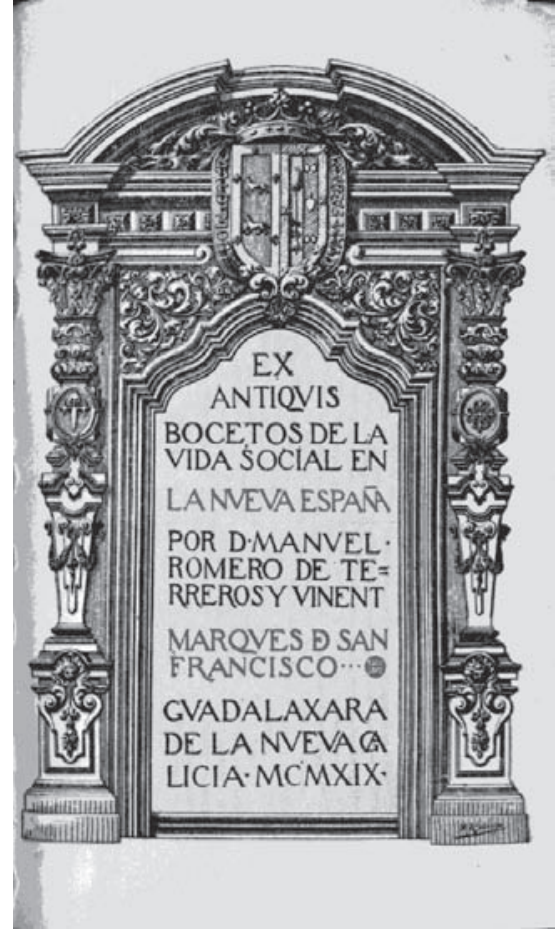

Portada de Ex antiquis. Bocetos de la vida social en Nueva España, de Romero de Terreros. cionaria como una manifestación más de la oposición a los proyectos o planteamientos de signo liberal y positivista que al menos desde fines del siglo XIX agitó la vida cultural en Hispanoamérica. La exaltación de la raíz hispánica de México equivalía a indagar en la tradición para saber algo más de la identidad nacional y para crear una expresión artística propia, concebida desde planteamientos que daban especial relieve a los ideales más altos frente al materialismo contemporáneo, en una actitud muy extendida entre los intelectuales hispanoamericanos del momento. En el solar hispano se encontrarían, pues, las raíces de la raza, en busca de las cuales los escritores viajaron con frecuencia, aunque en rigor los colonialistas mexicanos no necesitaban cruzar el Atlántico, como el mismo Cravioto dejaba de manifiesto en su poema:

3 Ibid., p. 195. Eso no significa que no encontraran en el "solar hispano», cuando se les presentó la oportunidad, lo mismo que buscaban en el pasado colonial: en Viajes alucinados. Rincones de España (México, Editorial Cvltura, 1924, p. 8), Manuel Toussaint aseguraba que él mismo, «sin los prejuicios de las civilizaciones europeas, que al cabo resultan fallidas, pudo hallar en los remotos pueblos de España, vírgenes ante el anhelo de quien sabe disfrutarlos, campo más hondo, más acogedor a sus emociones》.

4

Artemio de Valle-Arizpe, La muy noble y leal ciudad de México, según relatos de antaño y de hogaño, México, Editorial Cvltvra, 1924, pp. XI-XII.

5 Ibid., p. XIV.

6

Genaro Estrada, Visionario de la Nueva España. Fantasías mexicanas, México, Ediciones México Moderno, MCMXXI, pp. 16-17.

El pasado mexicano en la literatura "colonialista"

TEODOSIO FERNÁNDEZ
Nueva España es la madre, y en su lenguaje obscuro nutren nuestras raíces más puras y más hondas las savias que en el tiempo convertiranse en frondas, las yemas que en las horas columpiarán corimbos y las chispas sagradas que pronto serán nimbos. ${ }^{3}$

Indagar en la significación de ese seno materno novohispano era la forma de comprender el presente y contribuir a la conformación del futuro. La relación con el modernismo, por otra parte, resulta aún más profunda si se tiene en cuenta que el esteticismo aristocrático que había alejado de su entorno a los escritores no era ajeno a la actitud de estos intelectuales que, ajenos en apariencia a la acción política, dedicaban su vida a investigar el pasado, incorporándose a un proceso cultural que derivaba de lo cosmopolita hacia lo propio sin renunciar a su interés en los paisajes y en las atmósferas de inspiración literaria o artística, proceso que constituyó una de las facetas más relevantes del posmodernismo. El México virreinal se convirtió así en el tema fundamental de la literatura colonialista, y escenarios, objetos y personajes lejanos atrajeron la atención de los escritores, eruditos que viajaban a tiempos pretéritos en busca de emociones estéticas que el presente no les ofrecía. A ese respecto resultan de notable interés los testimonios que Artemio de
Valle-Arizpe reunió en La muy noble y leal ciudad de México, según relatos de antaño y de hogaño, con aportaciones de épocas muy diversas: desde Hernán Cortés, Bernal Díaz del Castillo y «El conquistador anónimo» hasta Manuel Toussaint y Genaro Estrada, sin olvidar, desde luego, a González Obregón y Romero de Terreros. Mención especial merece la «Introducción» del antólogo, en la que se resumía el proceso que llevó desde la ciudad indígena que vieron los conquistadores a otra en la que la desmedida afición al lujo determinó que se dieran «severas pragmáticas» para contenerlo, cierto que sin mayor éxito, y más cuando «si mucha era la magnificencia de las casas, era más grande aún la de las iglesias y conventos ${ }^{4}$, para culminar con la contribución del propio De Valle-Arizpe a la configuración de la imagen de la capital novohispana que entonces se divulgaba: sólo interrumpido por las fiestas y alguna vez por noticias que animaban las conversaciones, «el vivir era todo paz dulce y todo quietud benigna, entre la sombra perfumada de tantas iglesias y entre tantos conventos y entre tantas casas nobiliarias e insignes. Un encanto sosegado sahumaba toda la ciudad. La vida se deslizaba apacible y buena, con espaciosa dulzura, entre una gran quietud espiritual y se anegaba en gran placidez» ${ }^{5}$.

Con esos planteamientos u otros similares, buena parte de la literatura colonialista había de dedicarse a describir la ciudad de México durante el virreinato, tarea sólo posible para quienes habían conseguido un conocimiento minucioso de esos tiempos pasados. No en vano aquella tradición era «casi siempre libresca y fantasmagórica», como Genaro Estrada aseguraba en las primeras páginas de Visionario de la Nueva España, uno de los libros más representativos de aquel esfuerzo para comprender una ciudad que encerraba «el alma de los siglos», alma cuya esencia había que captar y convertir «en expresión artística» ${ }^{6}$. Para ello nada mejor que reunir a tres espíritus sensibles en las torres de la catedral, cuando el crepúsculo de la tarde ilumina sobre la ciudad ensombrecida las torres de iglesias $\mathrm{y}$ conventos o los remates que se elevan sobre las fachadas de los viejos palacios: ese momento mágico basta para que se animen antiguas escenas en las que cobran vida virreyes y virreinas, oidores y corsarios, palaciegos serviles y bergantes hijos de conquistadores, clérigos y monjas, señoras piadosas y muchachas enamoradas, en un ambiente entre cortesano y monacal, de fiestas abundantes y sobre 
todo de siestas que pueden alentar el sueño de encontrar tesoros aztecas ocultos o hacer que se animen los santos de un altar churrigueresco. La capital no es el único escenario posible -se puede viajar a Guatemala en busca de Bernal Díaz del Castillo, para recuperar con su ayuda la magnífica ciudad prehispánica, o asistir a la llegada de la nao de la China, con su cargamento de seda y de canela, de porcelanas $\mathrm{y}$ de otros valiosos productos de oriente-, pero allí están la magnificencia de la catedral y la plaza, los numerosos campanarios que suenan en una acordada oración, las casas que hacen sentir a veces una atmósfera fúnebre de ruinas, los lugares recónditos y silenciosos en los que puede captarse la presencia de las ánimas y los fantasmas, las calles donde las gentes manifiestan su temor ante el cometa que anuncia calamidades, sin que la nostalgia del tiempo ido impida recobrarlo a veces con humor ni manifestar indudable simpatía por quienes alteraron aquel orden, desde el fraile agustino que lee al prohibido Erasmo hasta los insurgentes que provocarían el fin del virreinato.

Con el fin de ganar el interés de los lectores se intentó con frecuencia, como en Visionario de la Nueva España, conjugar las descripciones con el relato de anécdotas, que desde $E l$ madrigal de Cetina y El secreto de la "Escala" (1918), de Francisco Monterde, trataron de aprovechar el renombre de algunos personajes del mundo novohispano. Los colonialistas no se diferenciaban en esto de lo que habían hecho y seguían haciendo sus "precursores»: entre otros episodios de la vida novohispana, Romero de Terreros recogía en Ex antiquis el fin de don Fernando Fernández de Valenzuela y Enciso -el «Duende» que pretendiera ser valido de la reina madre doña Mariana de Austria, durante la minoría de edad de Carlos II-, desterrado en México cuando terminaba el siglo XVII y muerto allí a consecuencia de la patada de un caballo ${ }^{7}$. Los escritores habían de merecer especial atención, empezando por el «caballero de la negra ropilla» que estaba al servicio del virrey don Antonio de Mendoza y escribía comedias cuando reencontró a su amada, la de los «ojos claros, serenos» -una dama «de armoniosa hermosura: en su rostro de rasgos perfectos dominaban los ojos de azul angélico»8- al llegar ésta a México con su marido, el visitador de la Real Audiencia encargado de preparar el recibimiento a un nuevo virrey, don Luis de Velasco. Era precisamente Gutierre de Cetina quien descubría que tal visitador era sólo un farsante, y nada se sabría después del caballero poeta ni de la dama inspiradora del famoso madrigal ${ }^{9}$. Ese relato abrió el camino para otros de inspiración similar que trataron de fortalecer su carácter narrativo, como El corcovado. Un amor de don Juan Ruiz de Alarcón y Mendoza, donde Ermilo Abreu Gómez se ocupaba del amor del gran dramaturgo novohispano por doña Clara de Cienfuegos y Horcasitas, «ricahembra de agraciado parecer, linajuda casta y preclara calidad de sangre, con humos y ribetes de infanzona» ${ }^{10}$, y además -es buena ocasión para dejar de manifiesto las peculiaridades estilísticas del autor, peculiaridades que constituían la aspiración final del escritor colonialista- con

sus pujos y capítulos en eso de los amores con barruntos trágicos, sus caprichos nebulosos con algo de brujería y muy refinada lascivia conventual, en donde figuran, con perdón de sus mercedes, amén de otros recatados y justísimos varones, un cierto Capitán de Lanceros, el desasosiego de un melindroso Chantre de Catedral, y hasta la malandanza de un no menos puntilloso y resalado Oidor de la Real Audiencia. Bolonias lenguas añaden quisicosas de gitanería, resabios birjanescos que ayuntan el nombre de un enviso y garboso Revisor de la Concepción con la vergüenza de un rorro canijo concebido a escote entre muchos y que oculta sus plañideros lloros en el maternal regazo de fingida tía hurgamatrices y lameplatos de cierto soterrado convento... ${ }^{11}$

La historia culmina y concluye cuando Ruiz de Alarcón sube esperanzado la escalera que conduce a los aposentos de la dama:

En el primer descanso creyó descubrir su olfato, el fino vaho de un cuerpo femenino, encendiendo en sus venas la hoguera de los carnales apetitos que sólo es dado apagar en la venusina fuente del placer. Continuó la ascensión y ya finaba la jornada cuando sintió sobre sus espaldas -amuleto y alcancía- suave mano que se posaba y resbalaba con fanática religiosidad, mientras dulce y velada voz repetía tres veces en el apacible silencio:

- iMartes de San Antonio, sedme propicio!

En la penumbra brillaron los enrojecidos ojazos de la diablesa.

Y el corazón del burlado doncel fue el hozadero de los jabalíes del dolor.

El zaguán se abrió frente a don Juan como para dejarle el paso franco.

Y por un instante la sevillana daga de provecho medio oculta en el cinto burló su labrada cárcel de pedrería ${ }^{12}$.
Véase «El Duende», en Ex antiquis. Bocetos de la vida social en la Nueva España, por Manuel Romero de Terreros y Vinent, Marqués de San Francisco, Gvadalaxara de la Nueva Galicia (Casa de Fortino Jaime), MCMXIX, pp. 175-181.

8 Véase «El madrigal de Cetina», en Francisco Monterde, Páginas escogidas, México, B. Costa Amic Editor, 1969, pp. 25-58 (42 y 45)

9

Cuando Monterde escribió ese relato apenas se disponía de datos sobre la estancia de Gutierre de Cetina en México (véase al respecto "Gutierre de Cetina» y "Proceso del heridor de Cetina» en Sucesos reales que parecen imaginados de Gutierre de $\mathrm{Ce}$ tina, Juan de la Cueva y Mateo Alemán. Los refiere y comenta Francisco A. de Icaza. Madrid Imprenta de Fontanet, 1919, pp. 17-75 y 209-241). De Valle-Arizpe contaba ya con la información sobre la muerte del poeta en Puebla de los Ángeles cuando relacionó su desgracia con sus amores con doña Leonor de Osma, que "era feílla, pero provocativa y apetitosa la muy sinvergüenza»; véase "Ojos claros, serenos...», en Artemio de Valle-Arizpe, Amores y picardias. Leyendas, tradiciones y sucedidos del México virrei nal, Madrid, Biblioteca Nueva, 1932, pp. 17-36 (17).

10

Ermilo Abreu Gómez, El Corcovado. Un amor de don Juan Ruiz de Alarcón y Mendoza, prólogo de Alfonso Reyes, México, E. Gómez de la Puente Editor, 1923, p. 26.

11 El Corcovado, p. 30.

12 Ibid., p. 44

El pasado mexicano en la literatura «colonialista"

TEODOSIO FERNÁNDEZ 


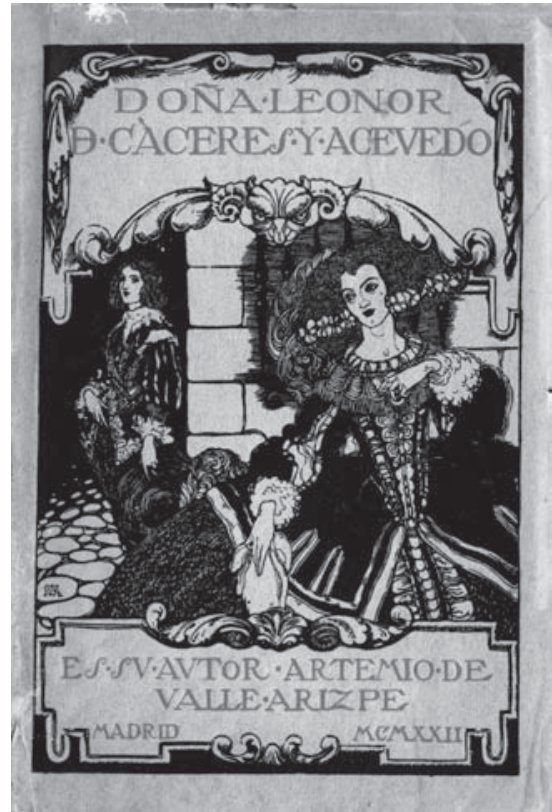

Portada de Doña Leonor de Cáceres y Acevedo, de Artemio de Valle-Arizpe.

13

Ibid., p. 13

14

Visionario de la Nueva España, op. cit., p. 13.

15

Artemio de Valle-Arizpe, Doña Leonor de Cáceres y Aceve do y Cosas tenedes..., Madrid, Tipografía Artística, MCMXXII, p. 13.

16

Sin duda Sor Juana Inés de la Cruz fue una de las figuras más atractivas para los colonialistas, que además contribuían significativamente a su rescate. En esa tarea destacó especialmente Manuel Toussaint, editor de Poesías escogidas de Sor Juana Inés de la Cruz (1916), de Poemas inéditos, desconocidos y muy raros de Sor Juana Inés de la Cruz, la Décima Musa (1926) y, sobre todo, de Obras escogidas. Respuesta a Sor Filotea de la Cruz (1928).

17

Doña Leonor de Cáceres..., op. cit., p. 132. Don Carlos de Sigüenza y Góngora aparece como el albacea testamentario del adusto personaje. Sor Juana habría sido la «íntima tragedia» (p. 131) del coleccionista, «Doctor subtil de toda teología en la Real y Pontificia Universidad de México, de la que llegó a

El pasado mexicano en la literatura "colonialista"

TEODOSIO FERNÁNDEZ
Ésa fue la razón por la que don Juan Ruiz de Alarcón y Mendoza viajó a la metrópoli en el séquito del virrey don Luis de Velasco. «Algo largo el cuento para el suceso: mucho deleite de ensartar palabras por el gusto de hacerlo» ${ }^{13}$, resumiría en su «carta-prólogo» Alfonso Reyes, nada convencido de la necesidad de esos dispendios estilísticos cuando se dedicaban a insistir en la tradición de una lengua y no a innovarla. En cuanto al primero de esos reparos, afectaba a una aspiración fundamental del narrador colonialista, que Genaro Estrada resumió para sí mismo y para los demás: «Su ideal sería escribir una novela sobre el breve tema de una miniatura del siglo XVII o del pañuelo de encajes de una virreina» ${ }^{14}$. Artemio de ValleArizpe ya había mostrado esa tendencia o debilidad de manera aún más acusada en Doña Leonor de Cáceres y Acevedo (1922), cuya protagonista le parecía al narrador de ésas «que llaman daifas, mozas del partido, gordeñas, suripantas o tusonas, que dan a la torpeza de la carne haciendo de su cuerpo la más infame finca de su deshonra que venden a dineros» ${ }^{15}$, sin que esa prometedora presentación se tradujera luego en resultados de interés. El relato era más bien un diálogo -tras la introducción, lo constituían básicamente las conversaciones de doña Leonor con sus amigos Alonso Martín de Ibarra y Lorenzo Ceinos-que llegaba a su fin cuando esa mujer depravada, verdaderamente enamorada por una vez, enloquecía al saber que había yacido con un ser de ultratumba. De Valle-Arizpe propendía también a lo fantástico en Cosas tenedes..., otro diálogo incluido en el mismo volumen donde Ramiro López de Agurto y el licenciado don Diego Laynes hablaban mucho de sor Juana Inés de la Cruz ${ }^{16}$ y menos de Carlos de Sigüenza y Góngora, y que con-

\footnotetext{
ser Maestrescuela con general contento y aplauso de los doctos» (p. 119). Eso da pie a una interpretación de los sonetos amorosos de sor Juana, según afirma don Ramiro: "Juana de Asbaje tenía, sí, qué duda cabe, altos amores imposibles, era fiel guardesa de los ocultos sentires de una pasión que nadie conoció» (p. 181).
}

cluía cuando el primero de esos interlocutores estaba a punto de morir tras ser brutalmente golpeado por el personaje de un cuadro que representaba a su tío don Juan Jerónimo López de Agurto, "feo, erudito y enamorado» ${ }^{17}$ que en su día habría aspirado sin éxito a la mano de Juana de Asbaje y habría gastado su fortuna adquiriendo los libros raros y curiosos de la monja jerónima y los del Arzobispo doctor Francisco de Aguiar y Seixas.

La fascinante personalidad de Juana de Asbaje estuvo con frecuencia detrás del interés que los escritores colonialistas fijaron en los ámbitos conventuales y en sus habitantes, y buena prueba de ello puede encontrarse en Sor Adoración del Divino Verbo, "crónica de una vida imaginaria en el Virreynato de la Nueva España, ofrendada a la memoria de la muy ilustre Madre Juana Inés de la Cruz, religiosa profesa en el convento de Santa Clara de la Orden de San Jerónimo», novela en la que Julio Jiménez Rueda desarrolló episodios que bien pudo haber protagonizado la excepcional escritora novohispana, por algún momento presente en la obra: también profundas inquietudes espirituales guiaron en la ficción a Clara Isabel Suárez de Figueroa desde la alquería familiar hasta el convento, pasando por las experiencias vividas en la corte virreinal, buen pretexto para describir el abigarrado colorido de las calles de México, animado por procesiones, mascaradas y autos de fe, y para recrear la licenciosa corte virreinal, de cuyos peligros escapaba a duras penas la protagonista. Significativamente, el proceso relatado mostraba un parentesco notable con el que Jiménez Rueda resumía en Camino de perfección, «Tríptico de la vida de la Madre Juana Inés de la Cruz» publicado junto a Sor Adoración del Divino Verbo ${ }^{18}$, y donde la vida de la celebrada monja novohispana resultó limitada a tres momentos sucesivos de renuncia: al amor, a los libros, a la vida. Que obras como ésas no respondían a un interés «ortodoxo» por la vida del espíritu queda demostrado por la contigüidad de los temas citados con otros como el abordado en La vida milagrosa del venerable siervo de Dios Gregorio López, donde Ermilo Abreu Gómez se ocupaba de ese personaje nacido en Madrid en 1542 y fallecido en México en 1596, cuando gobernaba el virrey Luis de Velasco: un personaje misterioso que hizo vida de ermitaño en Santa Fe, un lugar próximo a la ciudad de México que llegó a convertirse en centro de peregrinación, y quien, alguna vez sospechoso de judaizante o de «alumbrado», alcanzó la condición de 
«Venerable» tras haberse abierto el correspondiente proceso de canonización. Abreu Gómez se acercaba así -con escaso acierto-al territorio oscuro y atractivo de la heterodoxia, que encontró su mejor concreción en la novela de Julio Jiménez Rueda titulada Moisén, «bello poema» dedicado a recrear «la atmósfera recatada y temerosa del virreinato de la Nueva España», para utilizar palabras con las que Antonio Caso presentaba el libro ${ }^{19}$. El relato se inspiraba en los autos con que el Santo Oficio, con una intención política evidente, persiguió a los judíos o judaizantes de México entre 1642 y $1649^{20}$ : los encausados eran en su mayoría originarios de Portugal, que acababa de recuperar su independencia, y conspiraban más o menos abiertamente contra España. Entre los propósitos del autor no estaban los de analizar aquella circunstancia, aunque no faltaran referencias a ella, ni los de aprobar o condenar a los judíos o a la Inquisición: más bien parecían interesarle sobre todo esas formas exacerbadas o fanáticas de la fe con que los unos trataban de justificar la hechicería, el sadismo e incluso el crimen, y los otros la crueldad de las torturas con que arrancaban a aquellos las confesiones; al final, además, parecía prevalecer el propósito de ofrecer una estampa melancólica del pasado, propósito que encontró su manifestación mejor cuando el relato se acercaba a su conclusión, mientras caía la noche y ante los supervivientes se adivinaba el triste destino de remar en galeras para los hombres o servir a las monjas de los conventos de España para las mujeres.

Tanto los colonialistas como sus «precursores» demostraron un gran interés por esos temas, que estuvieron lejos de agotarse. Con ellos guardaban siempre alguna relación las «figuras romancescas» de aquellos tiempos que -«como el Santo Felipe de las Casas, el pícaro Martín Garatuza, la encantadora Juana Inés de la Cruz, la hombruna monja Alférez, el alucinado D. Guillén de Lampart y tantas otras»- Abreu Gómez mencionaba en un «Elogio de don Luis González Obregón», incluido en La vida milagrosa del venerable siervo de Dios Gregorio López, para pedir a su erudito compatriota que no abandonara sus pinceles y los empleara en pintarlas, convencido de que, evocadas por él, «formarían una galería de óleos interesantísimos» ${ }^{21}$. Algunos de esos personajes, insólitos o marginales, vacilantes con frecuencia entre las exigencias del espíritu y las debilidades de la carne, revelan un significativo parentesco con otros de ficción, entre los que cabe incluir esas mujeres

perversas y mórbidas en versión hispánica llamadas Leonor de Cáceres y Acevedo o Clara de Cienfuegos y Horcasitas, protagonistas de anécdotas que ignoran los límites entre lo histórico y lo legendario e incluso fantástico: no más que otras que habían inquietado el mundo colonial, como la perturbadora «mulata de Córdoba», perennemente joven y cuyos extraños poderes le permitieron escapar de las cárceles de la Inquisición ${ }^{22}$

Pero corría ya el año 1925 cuando De Valle-Arizpe animaba a González Obregón a proseguir la tarea, y el tiempo del colonialismo estaba a punto de agotarse. Aún había de producir otra de sus obras más relevantes, a la vez resumen y parodia de las aportaciones realizadas: Pero Galín, novela donde Genaro Estrada podía evocarse escribiendo Visionario de la Nueva España al recordar el desarrollo de

una literatura que engordaba a ojos vistas con el evidente saqueo de esas sabrosas crónicas y leyendas en que son maestros reconocidos en América el peruano Palma y el mexicano González Obregón. Fue el desenterramiento de toda una guardarropía. Desenterráronse prelados y monjas, cerámica de la China, galeones españoles, oidores y virreyes, palaciegos y truhanes, palanquines, tafetanes, juegos de cañas, quemaderos inquisitoriales, hechiceras, cordobanes, escudos de armas, Gacetas del 700, pendones, especiería, sillas de coro, marmajeras, re-

19

Julio Jiménez Rueda, Moisén Historias de Judaizantes e Inquisidores que vivieron en la Nueva España al promediar el siglo XVII. Las saca a luz el licenciado Julio Jiménez Rueda, abogado y vecino natural de la ciudad de México y le pone prólogo el Lic. Antonio Caso profesor de la Universidad, México, Editorial "Cvltura», 1924 , p. 10

\section{0}

Jiménez Rueda, que había encontrado inspiración para su Moisén y para algunos pasajes de Sor Adoración del Divino Verbo en México viejo, 1521 1821 (1910) y en los tomos $\checkmark$ (La Inquisición en México, 1906) y XXVIII (Autos de fe de la Inquisición de México con extractos de sus causas. 1646-1648, 1910) de los Documentos inéditos o muy raros para la historia de México reunidos por Genaro García, aprovecharía la información disponible para resumir esos procesos en su libro Herejías y supersticiones en la Nueva España (los heterodoxos en México), México, Imprenta Universitaria, 1946, pp. 119138.

21

Véase La vida milagrosa del venerable siervo de Dios Gregorio López. La escribió Ermilo Abreu Gómez y se publica con un prólogo del licenciado don Artemio de Valle-Arizpe, México, Talleres Linotipográfi- cos Carlos Rivadeneyra, 1925 p. 30. De uno de los personajes mencionados por Abreu Gómez ya se había ocupado ampliamente Luis González Obregón en $D$. Guillén de Lampart. La Inquisición y la Independencia en el siglo XVII (París, Librería de la Viuda de C. Bouret, 1908). Tras llegar a México entre la servidumbre del virrey don Diego López Cabrera y Bobadilla, Duque de Escalona y Marqués de Villena, Lampart se vio enredado en la antes mencionada represión del Santo Oficio que la rebelión e independencia de Portugal, a finales de 1640, acarreó sobre los judíos portugueses afincados en México. En ese ambiente «meditaba y acariciaba la más atrevida de las empresas, la de hacer la independencia del reino y proclamarse, como él decía, Rey de la América y Emperador de los Mexicanos》 (p. 63). En 1642 la Inquisición lo acusó de recurrir al peyote y a la astrología judiciaria para predecir el futuro, así como de curar enfermedades con ayuda del demonio, por lo que fue condenado a la hoguera. Murió en el auto general de fe celebrado en México en 1649

22

Véase "La Mulata de Córdoba. Sucedido de la calle de la Perpetua», en Luis González Obregón, Las calles de México. I. Leyendas y sucedidos, tercera edición, México, Imprenta de Miguel León Sánchez, 1927, pp. 67-75.

El pasado mexicano en la literatura "colonialista"

TEODOSIO FERNÁNDEZ 
23

Genaro Estrada, Pero Galín, México, Editorial Cvltvra, 1926, pp. 20-21.

\section{4}

Ibid., p. 32

25

lbid., p. 34.

26

lbid., pp. 22-23.

27

Ibid., p. 38.

28

lbid., p. 152
El pasado mexicano en la literatura "colonialista"

TEODOSIO FERNÁNDEZ tratos en cera y mil cosas más, en apretada y chillante confusión $^{23}$.

La fascinación por el mundo virreinal se personificaba ahora en ese Pedro Galindo que, miembro de una familia de «la más elevada alcurnia» de su provinciana Solumaya de Chavira $-\mathrm{y}$ de rancio abolengo, pues los Galindo eran «descendientes todos de un español de la partida con que don Nuño de Guzmán asoló a los estados de Occidente, en el segundo tercio del siglo XVI» ${ }^{24}-$, se transformó en Pero Galín apenas llegado a la ciudad de México, adecuando su nombre al ambiente «de refinado arcaísmo, de elegante antigüedad, de vida superior ${ }^{25}$ en el que decidió sumergirse de inmediato. Ciertamente, Pero Galín ya no era una novela colonialista, sino una novela sobre el colonialismo que el mismo Estrada había cultivado. Podía evocar su propia imagen al relatar burlonamente que,

después de concienzuda rebusca de los giros más adecuados y de verificar nombres y citas, el escritor colonial coge la pluma y escribe:

«Esta es la verdadera crónica de lo que aconteció al Caballero de Santiago don Uriel de Lanzagorta, en ocasión de la publicidad de su relación que se imprime con el nombre de La famosa Villa de Meztitán y sus primitivos pobladores, y de los sucesos que verá el curioso lector en el curso de la misma."

El escritor colonialista se ha detenido un momento, para releer atentamente y, luego de meditar las palabras y de consultar el diccionario de la lengua y el de sinónimos, pone una raya en donde dice esta, cambia la palabra por la de aquesta; sustituye la frase de la publicidad por la de del aparecimiento; altera relación por mamotreto; imprime por estampa; sucesos por subcesos y misma por mesma, cambios todos que, a su juicio, han sido hechos con palabras coloniales hasta no poder más.

Y luego que ha escrito el rótulo, adornándolo de preciosos rasgos caligráficos, empieza su relación de esta manera:

«Habedes de saber que el anno Domini de mil y quinientos y ochenta y cuatro años»...

Aquélla fue, en la literatura mexicana, la hora del habedes ${ }^{26}$.

La parodia del colonialismo encontraba un blanco fácil en los excesos de la «fabla» utilizada -en los fragmentos antes citados de Artemio de Valle-Arizpe puede verse una buena muestra-, pero se centraba sobre todo en la condición extemporánea de los colonialistas, de algún modo representados por ese Pero Galín que llegó a ser «un anacrónico caballero del siglo XVII en una ciudad con automóviles, rotativas y estaciones de radio» ${ }^{27}$, y que entre burlas y veras permitía a Estrada mostrarse una vez más como un gran experto no sólo en las artes mayores y menores del virreinato, sino también en el comercio de antigüedades verdaderas y falsas que discurría por tiendas y calles de México, excelente ocasión para describir detalladamente el famoso mercado del Volador. Por supuesto, ese tiempo había concluido incluso para Pero Galín, a quien su amor por Lota Vera forzaría a encontrarse con la modernidad que le sobrevino al viajar a Estados Unidos, a Los Ángeles y a Hollywood, un mundo que el novelista demostraba conocer con la misma exactitud que el novohispano, y que su personaje asimilaría con rapidez y con el mismo fanatismo que antes había volcado sobre el pasado mexicano, no sin advertir las limitaciones espirituales de ese mundo reducible a tres virtudes o ideas llamadas «sistema, cooperación, disciplina» ${ }^{28}$. El regreso final a México había de permitirles optar por una modernidad distinta, de hacendados felices en un mundo campesino y feliz.

Estrada pretendía, sin duda, ofrecer a sus personajes y a México un futuro ajeno a la atracción incontrolada de lo antiguo o de lo moderno. Pero el colonialismo no entró en crisis tanto por esas razones como por el rumbo nacionalista que entonces tomaba la cultura del país, en el contexto de una discusión que legitimaría la novela sobre la Revolución Mexicana en perjuicio de otras opciones narrativas. Los colonialistas no fueron ajenos a esa crisis: con sus respectivos artículos «El afeminamiento de la cultura mexicana» y «Existe una literatura mexicana viril», publicados en El Universal Ilustrado el 20 y el 25 de diciembre de 1924, Julio Jiménez Rueda y Francisco Monterde habían contribuido al descrédito de la literatura que ellos mismos representaban y a dirigir la atención hacia Los de abajo, la novela de Mariano Azuela que iba a convertirse en referencia obligada de la narrativa revolucionaria, en un contexto nacionalista cada día más radicalmente hispanófobo.

Lo cierto es que el colonialismo perdió presencia de inmediato en el ámbito literario mexicano, aunque ofreciese de vez en cuando algunos frutos tardíos. Éstos fueron en gran medida un resultado de los esfuerzos de Artemio de Valle-Arizpe, quien en 1932 reunió otras historias curiosas en Amores y picardias y en 1942 dio a conocer la novela El Canillitas, donde relataba la vida y la muerte de Félix 
Vargas, "pícaro insigne, borracho esclarecido, ilustre profesor de gramática parda, hombre disparatado, que sabía más que Lepe, Lepijo y su hijo» ${ }^{29}$. Por otra parte, el interés de los colonialistas por el pasado novohispano derivó en atención hacia el pasado prehispánico, atención que ya se había manifestado en Cantos de Anábuac. Rapsodias y lirismos (1921), poemas que ocuparon a Cravioto después de escribir El alma de las cosas viejas, y que ahora podía apoyarse en el interés por las culturas indígenas que demostraban las leyendas mayas que Antonio Mediz Bolio recreó en Cuentos del faisán y del venado (1922) y las leyendas zapotecas que Andrés Henestrosa recogió en Los hombres que dispersó la danza (1929). Tras la huella de Miguel Ángel Asturias y José María González de Mendoza, que habían dado a conocer su versión del Popol Vub ${ }^{30}$, Mediz Bolio tradujo El libro de Chilam Balam de Chumayel, afianzando una atención hacia el pasado indígena que ya no dejaría de crecer. Fruto de ese interés fueron dos novelas más bien breves y tardías, que mostraban el deseo de inscribir el mundo prehispánico en la misma tradición que supuso el regreso al pasado colonial. Una de ellas es Canek: historia y leyenda de un héroe maya (1940), de Ermilo Abreu Gómez, quien, nacido en Mérida del Yucatán, ofrecía una dedicación creciente a la historia y la cultura de los indios de su tierra. Con esa dedicación ha de relacionarse su decisión de rescatar para la literatura a Jacinto Canek, protagonista de una revuelta indígena que tuvo lugar en 1761, en un relato de factura "poética» en el que el autor fundía los recuerdos de su infancia con elementos de la cultura o cosmovisión de los mayas -conocía bien el Popol Vub y los Libros de Chilam Balam-, para entonces condenados ya sin remisión a figurar entre los representantes del pensamiento mágico americano. Desde luego, Abreu Gómez no parecía plenamente consciente de ello, pues se limitaba a relacionar su relato con «las historias y las leyendas de la región» ${ }^{31}$, y tal vez el pensamiento de Canek constituía una aportación personal, con reflexiones como ésta:

Nosotros somos de la tierra; ellos son del viento. En nosotros maduran las semillas; en ellos se orean las ramas. Nosotros alimentamos las raíces; ellos alimentan las hojas. Bajo nuestras plantas caminan las aguas de los cenotes, olorosas a las manos de las vírgenes muertas. Sobre ellas se despeñan las voces de los guerreros que las ganaron. Nosotros somos la tierra. Ellos son el viento ${ }^{32}$.
"Canek, bueno o malo, es el libro que mejor revela mi dolor por el dolor de los humildes. Si su lectura aviva la conciencia del hombre frente a la injusticia, me tendré por satisfecho» ${ }^{33}$, explicaba Abreu Gómez, miembro de la Liga de Escritores y Artistas Revolucionarios (LEAR). La explotación colonial del indígena quedaba a cargo de los alcaldes que representaban el poder político, de los hacendados que detentaban el poder económico y de los curas -aunque no todos- leales a una jerarquía eclesiástica ajena a las virtudes que predicaba. Como puede deducirse, Abreu Gómez había derivado hacia los planteamientos que la LEAR exigía asumir.

Más acorde con el espíritu dominante en el colonialismo se mostraría otra novela más breve y también "poética», Moctezuma, el de la silla de oro (1945), donde Francisco Monterde no parecía especialmente interesado en resaltar la alevosía y la crueldad de los conquistadores: al cabo, Hernán Cortés «sólo tiene dos preocupaciones, que son las de cualquier español de su época: difundir su religión y adquirir más oro» ${ }^{34}$. En contraste con la magnanimidad de Moctezuma, resultaban evidentes y condenables la avaricia y el egoísmo de sus captores -incluso para ellos mismos-, sin que la novela se sumase a la hispanofobia que normalmente alentaba la exaltación del pasado indígena. El interés por el desdichado gran señor de Tenochtitlán también resultaba significativo en sí mismo, pues las circunstancias políticas y culturales mexicanas del momento no facilitaban la presentación «sin prejuicios» de su actuación - «no se pretende justificar, por supuesto, su indecisión y entrega ${ }^{35}$, aclaraba Monterde-, y algunos aspectos del relato invitan a situarlo en la estela del colonialismo. Uno de ellos es su conexión con el modernismo: «Si hay poesía en nuestra América, ella está en las cosas viejas: en Palenke y Utatlán, en el indio legendario y el inca sensual y fino, y en el gran Moctezuma de la silla de oro", había escrito Rubén Darío al presentar sus Prosas profanas, y esa opinión servía ahora para introducir la novela e inspiraba su título. Desde luego, su producción literaria demostraba claramente que Monterde no estaba dispuesto a limitar al mundo prehispánico sus fuentes de inspiración, pero lo relevante ahora es comprobar que hacía de la afirmación de Darío una lectura acorde con la visión colonialista del pasado que en ese momento se proyectaba sobre el último momento de esplendor del mundo azteca: «Del contraste entre el oscuro derrumbamiento y la anterior
29

Artemio de Valle-Arizpe, El Canillitas. Novela de burlas y donaires, México, Edición y Distribución Iberoamericana de Publicaciones (E.D.I.A.P.S.A.), 1944 , p. 444

30

Los dioses, los héroes y los hombres de Guatemala antigua o libro del Consejo, Popol Vuh de los indios quichés, traducción de la versión francesa de Georges Raynaud, París, París-América, 1927.

31

Canek. Historia y leyenda de un héroe maya, México, Ediciones Oasis, 33 ${ }^{\mathrm{a}}$ edición, 1977 [20 1969], p. 17.

32

Ibid., p. 90

33

Ibid., p. 20. Abreu Gómez incluyó esa historia en Héroes mayas. Zamná. Cocom. Canek advertencias de José Attolini y Andrés Henestrosa, México Compañía General Editora S A., Colección Mirasol, 1942. En Zamná se evocaba a ese "señor de los itzáes, derrotados por Kukulkán o Quetzalcóatl, 'la serpiente emplumada'». Por boca de Pedro Ché, portero del convento, en Cocom se recordaba a Nachi Cocom, quien se opuso a los verdugos de los miles de indígenas torturados $y$ a veces muertos por decisión de fray Diego de Landa en el auto de Maní, en 1562. En el volumen se incluía también unos Cuentos de Juan Pirulero.

34

Francisco Monterde, Moctezuma, el de la silla de oro, ilustraciones de Julio Prieto, México, Imprenta Universitaria, 1945, p 64 (edición facsimilar: México, Editorial Letras, 1971).

35

Ibid., p. 12. Monterde parecía necesitado de explicar su elección: «La debilidad de Moctezuma está compensada, en el cuadro de la época, por ventura para nosotros, con la valerosa decisión de Cuauhtémoc: héroe único, más adecuado para el drama que para la novela, por su vuelo magnífico y breve. En contras te con el vigoroso Cuauhtémoc está allí el débil Moctezuma que conmueve por su misma debilidad, causa de la derrota de su pueblo. Éste es el concepto dramático que de él se tiene, al evocarlo y animar las sombras que lo rodean» (id.).

El pasado mexicano en la literatura «colonialista"

TEODOSIO FERNÁNDEZ 


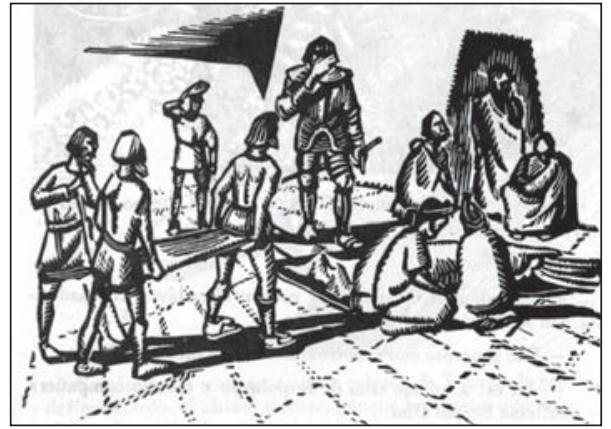

La muerte de Moctezuma. Ilustración de Julio Prieto para Moctezuma el de la silla de oro, de Francisco Monterde. brillante ostentación, se desprende esa melancólica poesía de lo pretérito, de la que habló Rubén Darío en la 'Palabras liminares' reproducidas como epígrafe» ${ }^{36}$. El esteticismo colonialista se había apoyado precisamente en el culto de un pasado caracterizado por alguna forma de «brillante ostentación», evidente en el prestigio de los objetos y monumentos antiguos o en la rareza de personajes que exhiben con fre36 Ibid., p. 5. Al escribir sus leyendas indígenas, Antonio Mediz Bolio ya había tratado de plasmar la «melancolía del pasado muerto, que se hace sentir, sin sentir, en las ruinas de las ciudades y en la tristeza del hijo de las grandes razas desaparecidas» (La tierra del faisán y del vena do, prólogo de Alfonso Reyes ornamentación de Cesáreo $F$ Díaz, Buenos Aires, Contreras y Sanz-Editores, 1922, p. V). Darío ya había proporcionado un epígrafe a Artemio de Valle-Arizpe, quien al introducir La muy noble y leal ciudad de México, según relatos de antaño y de hogaño había recordado estos versos de "Tutecotzimí» (El canto errante): «Al cavar en el suelo de la ciudad antigua, / la metálica punta de la piqueta choca / con una joya de oro, una labrada roca, / una flecha, un fetiche, un dios de forma ambigua, - los muros de un templo. M piqueta / trabaja en lo eterno de la América ignota».

37 Doña Leonor de Cáceres y Acevedo, op. cit., p. 101.

38

Véase Sor Adoración del Divino Verbo, op. cit., pp. 7-8. perdido, y que les confiere en el presente un carácter insólito.

Por lo demás, esa «melancólica poesía triste recuerdo de las razas vencidas no era diferente de la que impregnó con frecuencia la recuperación del México colonial. Un buen ejemplo puede encontrarse en la descripción de la «casa de las muertes» de Doña Leonor de Cáceres y Acevedo, y no sólo porque su patio «lleno de hierba y de abandono, con sus cipreses y viejos rosales y su fuente cantora, tenía mansas melancolías, una paz triste de cementerio aldeano» ${ }^{37}$. A veces esa atmósfera es la de espacios rurales como los que en su mocedad habitó Clara Isabel Suárez de Figueroa, «inclinada a la melancolía y a la meditación»: cuencia títulos cuya significación social se ha de lo pretérito» que parecía inseparable del no podía ser de otro modo en la alquería de San Juan de los Reyes, ante la campiña que recortaban al oriente los volcanes cubiertos de nieve, entre los repiques de las esquilas y la sinfonía de los pájaros, mientras al atardecer el ángelus apaciguaba las almas y voltejeaba «la campanita de plata» en el campanario de la iglesia ${ }^{38}$. El colonialismo coincidía así con otras manifestaciones literarias y artísticas de las primeras décadas del siglo Xx en la fascinación por las ciudades muertas o adormecidas, con sus casonas oscuras y lóbregas, con sus palacios en ruinas y sus calles solitarias donde podían arraigarse leyendas y tradiciones. $\mathrm{Al}$ entregarse a esa fascinación, el escritor podía sentir de algún modo su propio abolengo, su relación personal con esa hidalguía que significaba a la vez una manifestación de aristocracia intelectual y un rechazo a la mesocracia de su tiempo. En el caso de los colonialistas mexicanos, era también una forma de evasión de lo moderno que no renunciaba a lo nacional sino que lo situaba en otra época, de algún modo en una ciudad provinciana o antigua dentro de la ciudad moderna, donde los escritores podían sentirse languidecer con la venerable tradición colonial que hacían suya. Era su forma posmodernista de apresar el alma de México, de reivindicar el terruño, de proclamar la diferencia en la que creían que estribaba lo más auténtico y fundamental de su país y de su cultura. 